\title{
Introducing a Women's Health Clinic Improves Resident Comfort and Competence in Performing Women's Health Exams
}

\author{
Kristin A. Swedish, MD, MPH \\ Montefiore Medical Center, Bronx, NY, USA. \\ $\mathrm{J}$ Gen Intern Med 34(7):1081-2 \\ DOI: $10.1007 / \mathrm{s} 11606-019-04914-\mathrm{x}$ \\ () Society of General Internal Medicine 2019
}

\section{INTRODUCTION}

The American Board of Internal Medicine recognizes the importance of incorporating education and training in women's health into Internal Medicine (IM) residency. ${ }^{1}$ However, the inclusion of women's health topics in core IM curricula is inconsistent and has barriers, including lack of clinical exposure. ${ }^{2}$ The Women's Health Clinic (WHC) at Montefiore Wakefield Ambulatory Care Center was developed to incorporate education and training about women's health into the IM residency program, while also serving a vital need for our community. WHC occurs weekly and includes two to three residents on their month-long ambulatory care rotation. Each clinic session includes a 1-h didactic session, followed by residents seeing up to three patients with dedicated WHC appointments.

Montefiore Wakefield IM residents are international medical graduates. Their prior experiences in women's health care were typically limited to obstetric care. Prior to initiation of WHC, the majority of residents felt unprepared to do routine Pap smears, routine bimanual exams, or pelvic exams on symptomatic patients.

Our study assesses the effect of introducing WHC into the IM residency ambulatory care rotation on residents' comfort and competence in performing women's health exams.

\section{METHODS}

Albert Einstein College of Medicine Human Research Protection Program approved this project as exempt. Between November 19, 2015, and September 22, 2016, 52 IM residents participated in WHC for the first time. Residents of all years participated in the clinic at least once during their ambulatory month. Approximately 2 to 4 months following participation in $\mathrm{WHC}$, residents were surveyed to self-assess their competence and comfort level in performing clinical exams; residents were also asked how many pelvic exams they had done since WHC participation. Survey questions were adapted from prior surveys used in studies focused on teaching IM residents and internists about women's health. ${ }^{3,4}$

Published online March 11, 2019

\begin{abstract}
RESULTS
In its first 10 months, 109 patients were seen in WHC. The most common reason for visit was routine Pap smear, followed by vaginitis symptoms. Twenty-eight IM residents completed the post-WHC survey (56\% response rate). The majority of residents strongly agreed or agreed that they felt very well trained to do routine Pap smear (78.6\%), routine bimanual exam (71.4\%), and pelvic exam on symptomatic patient (78.6\%). Nearly $79 \%$ percent of respondents strongly agreed or agreed that they felt confident in obtaining sufficient endocervical sample most of the time when performing Pap smear (Fig. 1). The majority of residents felt that they could easily and alone perform pelvic exam $(64.3 \%)$, locate the cervix (71.4\%), and obtain an adequate Pap smear sample (71.4\%). However, only $25 \%$ felt they could easily perform wet mount alone (Fig. 2). In the 2 to 4 months following their WHC experience, surveyed residents had performed a median of three additional pelvic exams (range 0 to 4 ).
\end{abstract}

\section{DISCUSSION}

As international medical graduates, Montefiore Wakefield IM residents enter residency with variable prior education and training in women's health care. Participation in WHC increased their comfort and confidence in caring for female patients. In addition to being impactful on resident education, WHC was also feasible to implement in our academic primary care practice. We were able to devote one attending to the clinic each week without detracting from the ACGME-mandated precepting ratio. WHC itself only required equipment and supplies.

Study limitations include being a single clinic and our residents (all international medical graduates), which may not be generalizable to programs. The impact of such a program for American medical graduates may be less, as they enter residency with more didactic and clinical training in women's health care. Our study is also limited by poor response rate to the post-WHC survey (56\%). Those who did not complete the survey may have felt less confident in their skills, or simply less interested in the topic.

In conclusion, this study found that IM resident participation in WHC increased their comfort and confidence in women's health clinical skills. Further study is needed to 


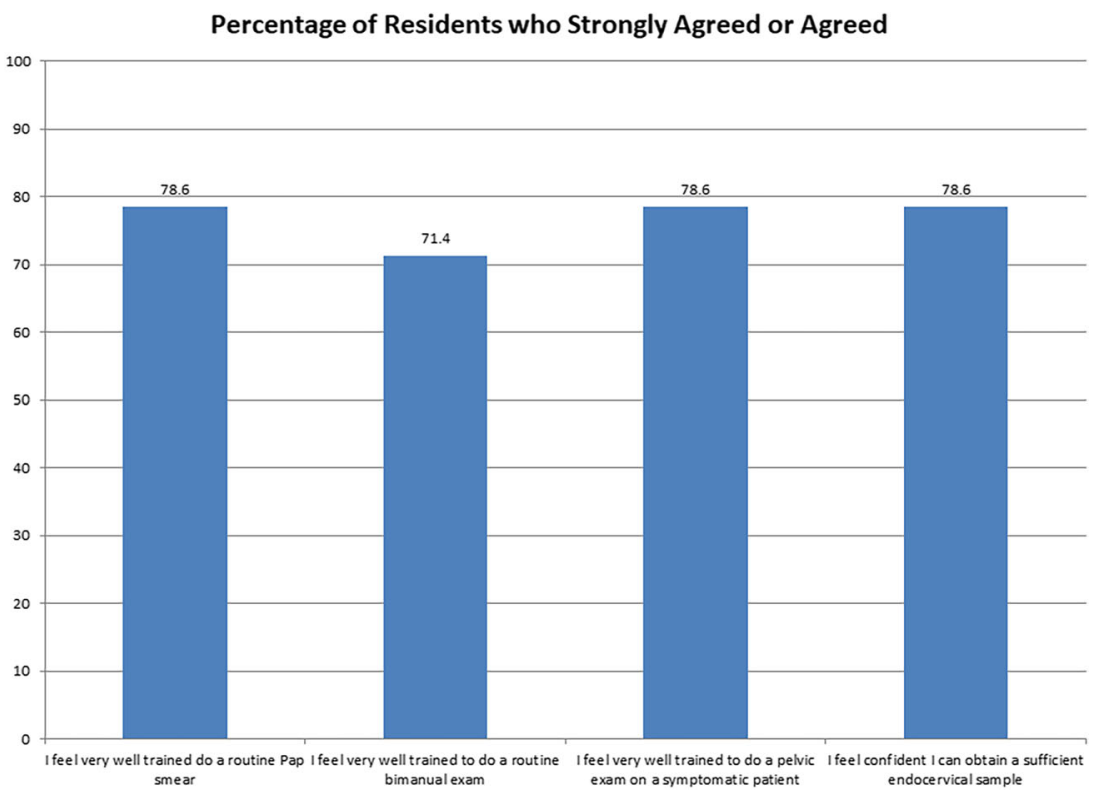

Figure 1 Percentage of residents who strongly agreed or agreed.

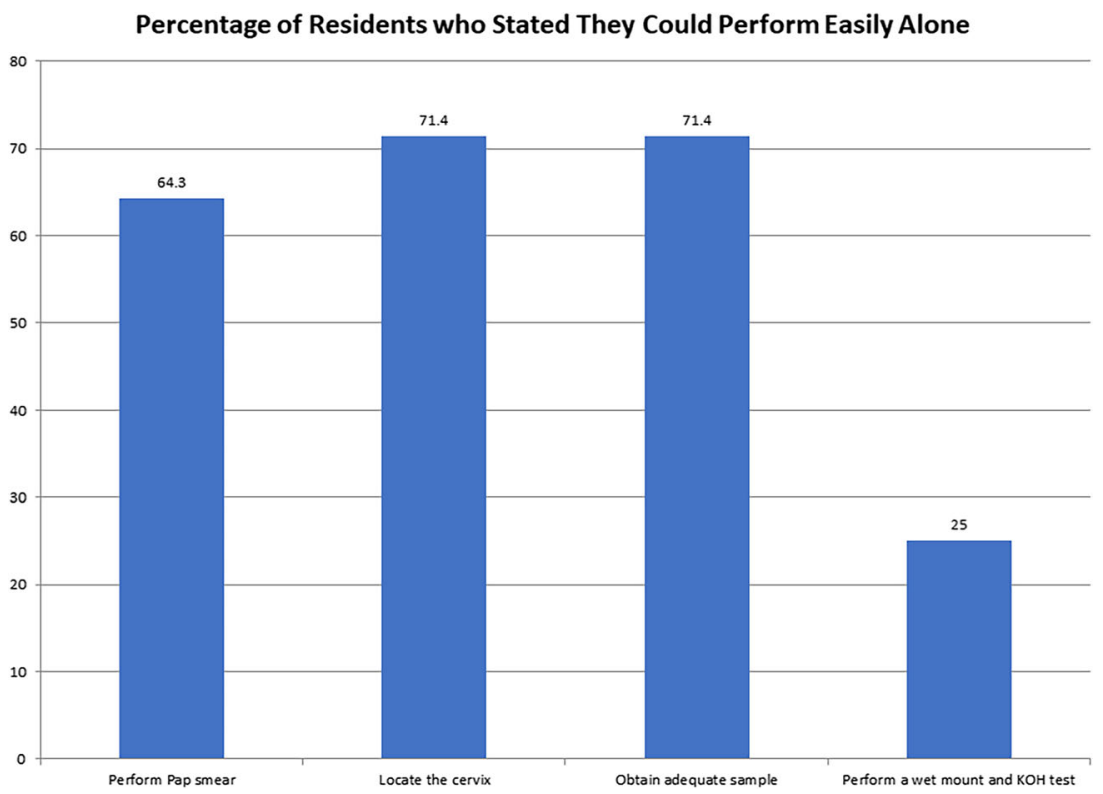

Figure 2 Percentage of residents who stated they could perform easily alone.

explore the long-term effects of participation, and if it is generalizable to other programs.

Corresponding Author: Kristin A. Swedish, MD, MPH; Montefiore Medical Center, Wakefield Campus, Bronx, NY, USA (e-mail: kswedish@montefiore.org).

\section{Compliance with Ethical Standards:}

Conflict of Interest: The author declares that she does not have a conflict of interest.

Publisher's Note: Springer Nature remains neutral with regard to jurisdictional claims in published maps and institutional affiliations.

\section{REFERENCES}

1. Day SC, Cassel CK, Kimball HR. Training internists in women's health: Recommendations for educators. Am J Med. 1996; 100: 375-9.

2. Casas RS, Hallett LD, Rich CA, Gerber MR, Battaglia TA. Program directors' perceptions of resident education in women's health: A national survey. J Womens Health. 2017; 26(2): 133-140.

3. Dixon JG, Bognar BA, Keyserling TC, et al. Teaching women's health skills: Confidence, attitudes, and practice patterns of academic generalist physicians. J Gen Intern Med. 2003; 18(6): 411-8.

4. Goldstein CE, Helenius I, Foldes C, McGinn T, Korenstein D. Internists training medical residents in pelvic examination: Impact of an educational program. Teach Learn Med. 2005; 17(3): 274-8. 